\title{
Management and Outcome of Bilateral Elastofibroma Dorsi: 3 Cases Report and Review of Literature
}

\author{
S. Karti, A. Jalal, A. Chfiri, A. Harti, M. Diouri
}

\section{ABSTRACT}

Elastofibroma dorsi is a rare soft tissues benign tumor with very slow evolution, seen predominantly in females and elderly, It mostly occurs in the infrascapular region, and can be bilateral. The diagnosis is based on clinical presentation and imaging features but pathological study after excision is necessary for confirmation. We present the cases of 3 patients with bilateral elastofibroma dorsi to clarify the clinical features, radiological and therapeutic modalities to improve management, along with a literature review.

Keywords: Benign, elastofibroma, soft tissues, tumor.

\section{INTRODUCTION}

Elastofibroma dorsi is a rare benign soft tissu tumor usually slow growing, typically located in the lower pole of the scapula, it is mostly seen in middle aged and older women. Elastofibroma Dorsi can be bilateral in 10 to $66 \%$ of cases.

The diagnosis can be both clinical and image based.

Magnetic resonance (MR) is most oftently used given its high sensitivity and specificity in soft tissues.

The surgical indication is made based on the patient's symptoms and the size of the tumor.

\section{CASE REPORT}

\section{A. Case 1}

A 65-year-old woman with no medical history, presenting two subscapular bilateral masses slowly growing for 7 years becoming painful.

The CT scan (Fig. 1) showed 2 subscapular nonhomogeneous mal limited masses with a density similar to muscles, including areas of lower density secondary to fat, measuring $48 \mathrm{~mm} / 24 \mathrm{~mm}$ on the right side and $44 \mathrm{~mm} / 24 \mathrm{~mm}$
Submitted : December 14, 2021

Published : January 19, 2022

ISSN: $2593-8339$

DOI: $10.24018 /$ ejmed.2022.4.1.1148

S. Karti*

Department of Plastic Surgery, UHC Ibn Rochd, Casablanca, Morocco. (e-mail: sarakarti1@gmail.com) A. Jalal

Department of Plastic Surgery, UHC Ibn Rochd, Casablanca, Morocco. (e-mail: amaljalal198604@gmail.com) A. Chfiri

Department of Plastic Surgery, UHC Ibn Rochd, Casablanca, Morocco. (e-mail: chfiri.asmaa@gmail.com) A. Harti

Department of Plastic Surgery, UHC Ibn Rochd, Casablanca, Morocco. M. Diouri

Department of Plastic Surgery, UHC Ibn Rochd, Casablanca, Morocco. (e-mail: moon.diouri @yahoo.fr)

*Corresponding Author

on the left side.

The decision to operate the patient was made due to the pain caused by the masses; a drain was left in place for 5 days post operatively. The patient presented a seroma post operatively, that was treated by multiple aspirations, and compression.

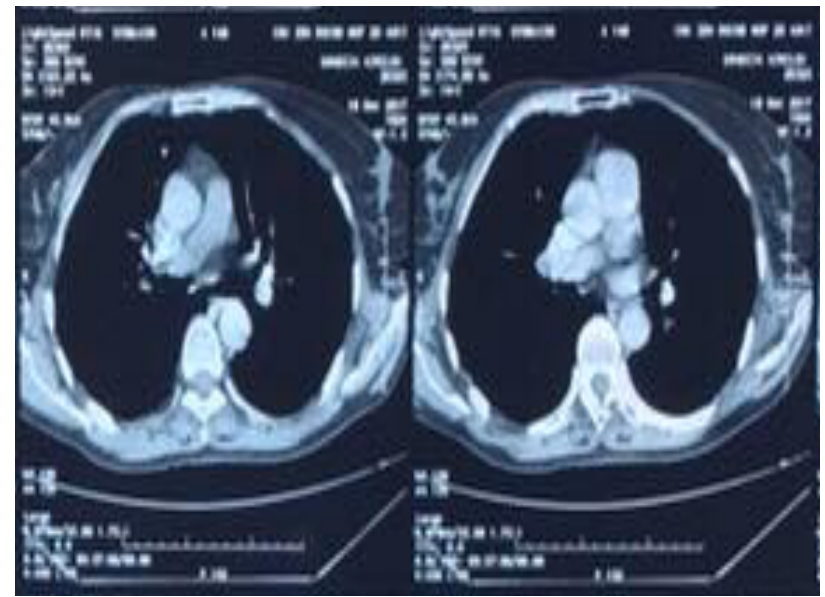

Fig. 1. CT scan image of bilateral elastofibroma dorsi. 


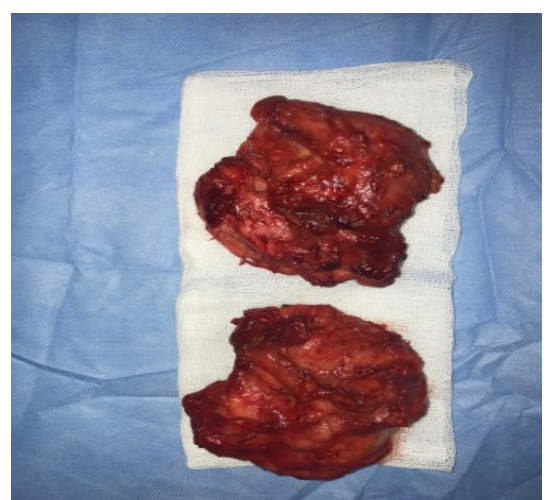

Fig. 2. The two excised masses.

\section{B. Case 2}

A 57 years old woman with no medical known history presenting two parascapular masses (Fig. 3) growing progressively for 5 years causing a discomfort in the right shoulder abduction.

The CT scan showed a bilateral aspect of elastofibroma dorsi.

The two masses were excised under general anesthesia, a drain was left on both sides for 5 days, and no complications were noted after surgery.

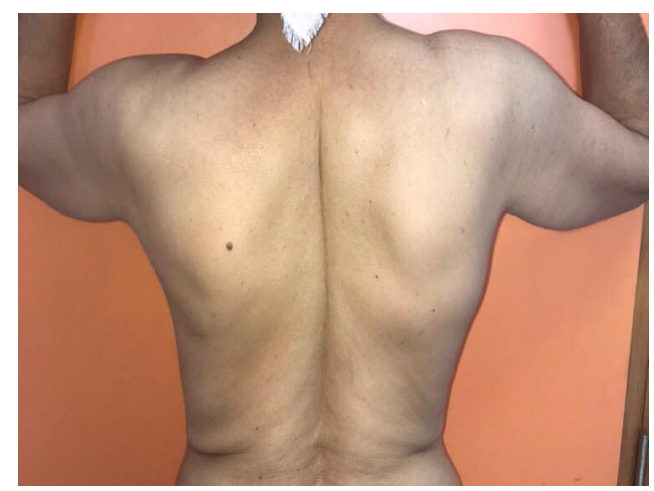

Fig. 3. 57 years old women with two parascapular masses.

\section{Case 3}

A 52 years old man with no medical history presenting three masses in the dorsal region two subscapular and one suprascaplar (Fig. 4)

The diagnosis was based on the $\mathrm{CT}$ scan showing a bilateral aspect of subscapular elastofibroma.

After surgery it appeared that the two subscapular masses were elastofibromas, and the third mass was a lipoma.

No complications were noted after surgery.

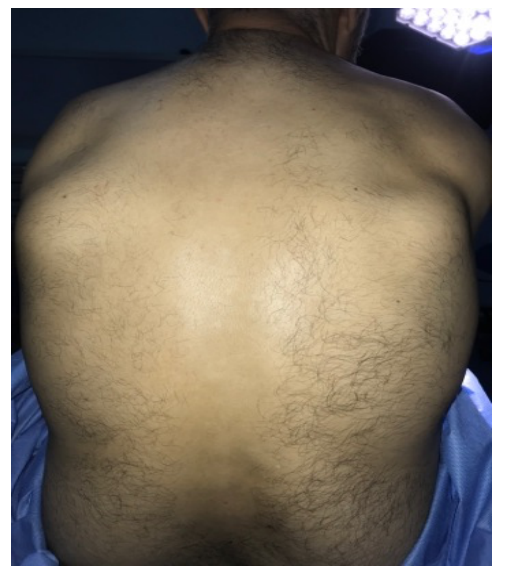

Fig. 4. 52 years old man with two parascapular masses.

\section{Discussion}

Elastofibroma Dorsi is a rare soft tissue tumor that grows very slowly, first described by Jarvi in 1961 [7], [8], It is typically located in the lower pole of the scapula, beneath the rhomboid major and latissimus dorsi muscles [7]-[9], but unusual locations such as ischial tuberosity, olecranon, thoracic wall, axilla, have been described in literature. In the subscapular region elastofibroma can be unilateral or bilateral in up to $66 \%$ [6], elastofibroma dorsi is more frequent in females over 55 years old more than males with a sex ratio that can vary from 5/4 to $13 / 1$ [6], [8], [9].

The World Health Organization in 2013 classified elastofibroma as a benign fibroblast/myofibroblast tumor [6], [8], [10].

Elastofibromas are believed to be a reactive process caused by microtraumas [5], [6] leading to overproduction of elastic tissue from fibroblasts stimulation.

A familial predisposition and chromosomal changes [6], [8] suggesting that this lesion may be considered a true neoplastic disease have also been proposed by authors for the development of elastofibroma dorsi. But its pathogenesis remains very controversial.

Elastofibroma dorsi tends to be asymptomatic [1], [2] and can be underdiagnosed because of its gentleness and slow growth rate, It can also present Pain and snapping in the scapula, accompanied by swelling and a subcutaneous bump [3], [10], In the presented cases all patients presented subcutaneous bumps in parascapular region, the first patient experienced pain, the second a discomfort in shoulder abduction, while the third was asymptomatic.

Accurate diagnosis of elastofibroma dorsi requires both anamnesis and imaging exams, which will determine the exact location and size of the tumor.

The physical examination reveals in typical elastofibroma dorsi a solid mass of variable size $(4-12 \mathrm{~cm})$, adherent to the deep layers but non adherent to the skin, more prominent in arm abduction, painless in most cases. Other soft tissu tumors can be suspected, especially sarcomas, therefore imaging study must be performed for diagnosis confirmation such as ultrasonography, CT scan and MRI [1], [4], [8].

MRI is considered to be the most accurate test for elastofibroma dorsi diagnosis [2]-[4] because of its higher sensitivity and specificity in recognizing soft-tissue, It appears as a non encapsulated mass with an alternating pattern of fibrous and fatty tissues, fibrous tissue produces low intensity signal in T1 and T2 while fatty tissue is seen as a high intensity signal in $\mathrm{T} 1$ and as an intermediate signal in T2 [2], [3], [6], [10], [12], gadolinium injection is not usually necessary. Biopsy is only performed when diagnosis can't be set in front of untypical MRI findings.

\section{A. Macroscopic Findings}

A poorly defined mass having a mean diameter between (4 to $12 \mathrm{~cm}$ ) with white fibrous tissue with interposing small areas of yellow fat.

\section{B. Microscopic Findings}

The lesion was composed of collagenous tissue, mixed with mature adipose tissue and eosinophilic elastic fibers fragmented into disks or globules with no signs of no atypia or mitotic activity [5]. 


\section{Immunohistochemical Findings}

An interesting immunohistochemical finding is the factor XIII a positivity in most cases; spindle cells can be CD34positive [5].

Treatment of elastofibroma consists in complete surgical excision of the mass [1], [6] with marginal resection, although the limit for surgical indication is still being discussed, but surgery is needed whenever the greater diameter is over $5 \mathrm{~cm}$ and in symptomatic cases [4]-[6], or when there is an important esthetic prejudice. Post operative wound drainage for a sufficient length in time seems to be necessary to avoid complications, our three patients underwent surgery.

The most common complications seen are seromas, and hematomas if a rigorous hemostasis is not achieved [4], [6], [10].

Some patients may experience a mild/moderate chronic pain along the surgical scar not referable to a single nerve distribution, unrelated to active mobilization of the shoulder

Which according to the literature, might be related to injury of the nociceptive system, that occurs during the surgical procedure, and might benefit from treatment by a specialist in pain therapy.

In our cases one patient had a seroma, while the two others did not present any complications.

There is no consensus in the literature about rehabilitation protocol after surgery [3], immobilization for 1 week, can help healing of muscle reattachments and can stabilize flaps, thereby helping to reduce complications, then passive ROM exercises after 15 days (Nanago).

The elastofibroma dorsi has excellent prognosis, extremely low recurrence, and no risk of malignant transformation has been reported in literature.

\section{CONCLUSION}

Bilateral elastofibroma dorsi is a rare benign tumor of soft tissue, it is more predominent in the parascapular region and amongst women, often asymtomatic the diagnosis is based on MRI, which is the most performent imaging exam, and anatomopathological examination is used for confirmation.

Résection decision depends on the symptoms evaluation, and the disconfort presented by the patient.

\section{REFERENCES}

[1] Bereni N, Carmassi M, Zinc J-V, Casanova D. Élastofibrome dorsal. À propos de 14 cas, et revue de la littérature. Ann Chir Plast Esthet. 2014; 59(4): 266-72. French.
[2] Briccoli A, Casadei R, Di Renzo M, Favale L, Bacchini P, Bertoni F. Elastofibroma dorsi. Surgery Today. 2000; 30(2): 147-152.

[3] Deveci MA, Özbarlas HS, Erdoğan KE, Biçer ÖS, Tekin M, Özkan C. Elastofibroma dorsi: Clinical evaluation of 61 cases and review of the literature. Acta Orthop Traumatol Turc. 2017; 51(1): 7-11.

[4] Karrakchou B, Yaikoubi Y, Chairi MS, Jalil A. Elastofibroma dorsi: case report and review of the literature. Pan Afr Med J. 2017; 28: 34.

[5] Tasli F, Vardar E, Argon A, Kabat T, Deniz S, Nart A, et al. Histochemical and immunohistochemical characteristics of elastofibromas. Pol J Pathol. 2014; 65(2): 120-4.

[6] Scamporlino A, Ruggiero C, Aramini B, Morandi U, Stefani A. Surgery for elastofibroma dorsi: optimizing the management of a benign tumor-an analysis of 70 cases. J Thorac Dis. 2020; 12(5): 18841894.

[7] Temel U, Gül Akgül A, Topçu S. Diffusion MR: A New Diagnostic Tool for Elastofibroma Dorsi. Sisli Etfal Hastan Tip Bul. 2020; 54(1): 103-107.

[8] Suliman MS, Higginbothom ZS, Amro A, McCorkle C, Saunders E. Elastofibroma Dorsi: A Rare Connective Tissue Tumor. Cureus. 2020; 12(2): e6874.

[9] Bartocci M, Dell'Atti C, Meacci E, Congedo MT, Magarelli N, Bonomo L, et al. Clinical features, imaging findings, treatment aspects of elastofibroma dorsi and long-term outcomes after surgical resection. Eur Rev Med Pharmacol Sci. 2017; 21(9): 2061-2068.

[10] Karakurt O, Kaplan T, Gunal N, Gulbahar G, Kocer B, Han S, et al. Elastofibroma dorsi management and outcomes: review of 16 cases. Interact Cardiovasc Thorac Surg. 2014; 18(2): 197-201.

[11] Pilge H, Hesper T, Holzapfel BM, Prodinger PM, Straub M, Krauspe R. Elastofibroma: clinical results after resection of a rare tumor entity. Orthop Rev (Pavia). 2014; 6(2): 5329.

[12] Özer D, Arikan Y, Gok C. Elastofibroma dorsi: evaluating the sufficiency of magnetic resonance in diagnosis and the time of surgical treatment. International Surgery Journal. 2019; 6(2): 388-391.

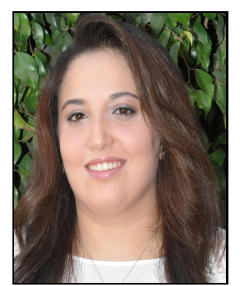

S.Karti born in Casablanca, Morocco, the 18th of May 1990 she obtained her medical degree in medical university of Casablanca in 2016 .

She is actually doing her residency in plastic surgery at Ibn Rochd university hospital in Casablanca. 